\title{
A Framework of Combined MCDM for Formulating Agenda-Setting in Overcoming Mining Conflicts
}

\author{
Achmad Farid Wadjdi ${ }^{1}$, Putri Hayuningtyas ${ }^{2}$ \\ \{farid.wajedi@kemhan.go.id ${ }^{1}$, ph.ajah@gmail.com ${ }^{2}$ \} \\ ${ }^{1,2}$ Research and Development Agency, Ministry of Defense, Indonesia
}

\begin{abstract}
The negative externality effects of government policies, such as foreign investment for mining exploration and extraction, can cause considerable inefficiencies in efforts to strengthen national defense. To overcome the problem, we propose a framework based on the BOCR approach that integrates AHP, DEMATEL, and FMEA to identify and evaluate the factors covered. AHP is directed to the fundamental questions related to the weighting of the hazard level, while DEMATEL is for the causal question related to the weighting of the likelihood of occurrence. Finally, FMEA is implemented to assess the priority of a risk-based sequential agenda as a cause and effect. A case study of the agendasetting to deal with negative externalities of foreign mining policies in Indonesia is presented as an example of the proposed MCDM framework. The results indicate that the proposed framework is useful in formulating the agenda-setting.
\end{abstract}

Keywords: agenda-setting, mining conflicts, multicriteria decision-making, public policy.

\section{Introduction}

The MCDM approach has become famous for decision making or policy formulation in dealing with conflicts in the mining sector and resource extraction. MCDM offers a structured and comprehensive framework for dealing with complex conflicts consisting of various interests and perspectives, various conflicting interests, various arguments in the form of data and information differences, and high uncertainty [1].

Furthermore, a framework that combines several MCDM techniques provides a believed, more accurate way to investigate, discover, and measure each consideration of various factors for comparing options [2]. In the last five years, where MCDM applications have been programmed into learning machine computing, a combination framework of several MCDM techniques has continued to be developed to facilitate the determination of weights through multi-respondent surveys, interviewing several informants, and Focus Group Discussions (FGD), or through the knowledge of several experts [3]. For specific decision making, a combination approach of several MCDM techniques involving many participants will continue to be able to enrich computational algorithms for various specific purposes, such as proposing agenda-setting.

This combination technique is widely used in various MCDM literature. The combination of MCDM techniques is interesting because each technique provides results with different interpretations, and then, that interpretation can be arranged into a scenario that is easily understood. This paper proposes a framework of FMEA (Failure Mode and Effects Analysis) 
that requires AHP (Analytic Hierarchy Process) and DEMATEL (the Decision-Making Trial and Evaluation Laboratory). AHP and DEMATEL can overcome shortcomings of the traditional FMEA techniques, which is a qualitative evaluation and does not consider the functional influence between components of a system, meaning that it cannot be applied to systemscomplicated influence relationships [4].

FMEA is a proactive technique for prospective risk analysis of high-risk processes. Its applications are currently extensive in various fields, such as the aircraft industry and the health care industry, including essential systems in the development and manufacture of medicines and the prevention of medication errors in hospitals [5]. In analysis with FMEA, three components of an assessment are needed. Severity, Opportunity, and risk Detectability. A result is a priority number (NPR).

DEMATEL was developed to visualize the structure of complex causal relationships through a matrix. It is useful in analyzing causal relationships between components of a system. It can also confirm interdependence among factors, help develop sketches that reflect relative relationships, and to investigate and solve complex problems. This method converts not only interdependent relationships into cause and effect groups but also finds important factors of complex structural systems with the help of impact relationship diagrams [6].

AHP has been a favorite decision tool for research in many fields, such as engineering, food, business, ecology, health, and government [7]. AHP constructs a decision-making problem in various hierarchies as the goal, criteria, sub-criteria, and decision alternatives. It performs pairwise comparisons to measure the relative importance of elements at each level of the hierarchy. Then, it evaluates alternatives at the lowest level of the hierarchy to make the best decision among multiple alternatives. AHP provides decision-makers with a way to transform subjective judgments into objective measures that Wadjdi et al. [8] make its data collecting form simple and ensure its consistency ratio.

The combination of the three weights is mapped so that it will form a series of causal-effects that can be scenarios. Before combining the weights, the factors are categorized by the BOCR (Benefits, Opportunity, Cost, Risk) approach [9]. In the context of the national security perspective, the resulting scenario can be used to predict the order of conflicts due to foreign investment policies. These scenarios can then be formed into the agenda-setting for government activities to anticipate the spread of conflicts.

Such MCDM combination techniques have been carried out, for example from two combinations, such as the fuzzy Delphi method - DEMATEL [10], AHP - DEMATEL [11], and DEMATEL - Fuzzy TOPSIS [12], or from three or more combination, such as DEMATELANP-TOPSIS [13], and TOPSIS - DEMATEL - FMEA [14].

There are different purposes and reasons for the combination, such as selection, identification of dominant factors, and decision making due to uncertainty, or to minimize mistakes or reasons to facilitate data collection. However, such a combination of the proposed framework to predict long-term risk and planning for solutions in the form of agenda-setting is rare, but later in this paper, we will show that it works.

Thus, this paper examines the proposed framework of combined FMEA-AHP-DEMATEL to evaluate the causal-effects of the factors identified and recommend the discourse of its potential solutions to influence and set policy agendas in Indonesia. From the perspective of national defense and security, the analysis includes analysis of dominant factors that can trigger conflict, and predictions of the types of conflicts in the future according to potential risk chains to support the goals of agenda-setting. To illustrate the framework, we present a case study of the national security perspective on foreign investment policy in the mining sector in Indonesia. 


\section{The Need for Agenda-Setting in Overcoming Mining Conflicts}

Identification of the causes of conflicts and their impacts is the first step in this study. In this paper, we define risk factors as issues that have the potential to cause conflict or cause conflict or cause factors. While other issues that arise as a result are called effect factors.

From the literature and the official documents, we list sixteen factors categorized according to the BOCR approach (Benefit, Opportunity, Cost, and Risk). About this approach, we are referring to Sarmiento \& Vargas-Berrones [9]. The following table shows the list of risks in the mining sector and extraction.

Table 1. The BOCR approach of mining issues in the National Security Perspective.

\begin{tabular}{|c|c|c|c|}
\hline Code & Issues & Category & Description \\
\hline R1 & $\begin{array}{l}\text { Population \& } \\
\text { social services }\end{array}$ & Risk & $\begin{array}{l}\text { Risk of unruliness due to social problems that arise: } \\
\text { migration/immigration, racial issues, and social gaps }\end{array}$ \\
\hline R2 & Criminal \& Order & Risk & Risks of crime and order, such as theft and smuggling \\
\hline R3 & $\begin{array}{l}\text { Natural disasters } \\
\& \text { work accidents }\end{array}$ & Risk & $\begin{array}{l}\text { Risk of natural disasters (landslides and explosions) and } \\
\text { workplace accidents }\end{array}$ \\
\hline R4 & Culture \& customs & Risk & $\begin{array}{l}\text { Risk of the behavior of foreign workers or migrants to the } \\
\text { habits of the local community }\end{array}$ \\
\hline R5 & $\begin{array}{l}\text { Agreement } \\
\text { violation }\end{array}$ & Risk & $\begin{array}{l}\text { The risk of public commotion, mutual suspicion, road } \\
\text { building, and protest due to breach of agreement }\end{array}$ \\
\hline $\mathrm{C} 1$ & Pollution \& Health & Cost & $\begin{array}{l}\text { Costs incurred by the government and the community due } \\
\text { to environmental damage and pollution that disturb health }\end{array}$ \\
\hline $\mathrm{C} 2$ & Inflation & Cost & $\begin{array}{l}\text { The impact of mining activity on socioeconomic outcomes } \\
\text { in local communities }\end{array}$ \\
\hline $\mathrm{C} 3$ & $\begin{array}{l}\text { Depletion of } \\
\text { resources }\end{array}$ & Cost & Cost of Loss or depletion of resources \\
\hline $\mathrm{O} 1$ & $\begin{array}{l}\text { Skills \& } \\
\text { Employment }\end{array}$ & Opportunity & Opportunities to improve skills \& employment \\
\hline $\mathrm{O} 2$ & $\begin{array}{l}\text { Consultation \& } \\
\text { communication }\end{array}$ & Opportunity & $\begin{array}{l}\text { Open opportunities for company, community and } \\
\text { government relations to communicate with each other }\end{array}$ \\
\hline $\mathrm{O} 3$ & Participation & Opportunity & $\begin{array}{l}\text { Opportunities for community involvement in managing } \\
\text { risk and conflict resolution }\end{array}$ \\
\hline $\mathrm{O} 4$ & Regulations & Opportunity & Opportunities for amending regulations \\
\hline B1 & Revenue \& tax & Benefit & Tax and revenue sharing \\
\hline B2 & Compensation & Benefit & Compensation for environmental impacts \\
\hline B3 & CSR & Benefit & $\begin{array}{l}\text { Corporate Social Responsibility for local and national } \\
\text { communities }\end{array}$ \\
\hline B4 & $\begin{array}{l}\text { Community } \\
\text { development \& } \\
\text { nationalism }\end{array}$ & Benefit & $\begin{array}{l}\text { Benefits of corporate \& government concern for the } \\
\text { development of local communities in the context of } \\
\text { national pride, nationalism, and patriotism }\end{array}$ \\
\hline
\end{tabular}




\section{Methods}

In short, the research framework is shown in Figure 1. The first to third steps are explained as follows:

\section{Step-1: Factors Identification}

Identification of factors that become mining issues, especially those involving foreign capital and foreign workers, was examined through literature studies and official documents (Ministry of Energy and Mineral Resources and local mining services) and subsequently these factors were confirmed with local Ministry of Defense representatives, "Kodim" representatives (Regional Military Command) or "Polda" (Regional Police) representatives. The results are outlined in Table 1.

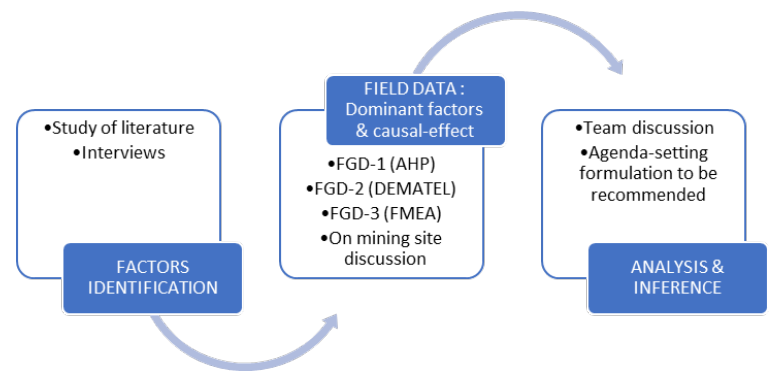

Fig. 1. The research framework.

\section{Step-2: Field Data}

We conducted data collection through three FGDs and limited discussion at the mine site. There are 20 participants from each focus group discussion (FGD) and a total of 60 participants. FGD was gathered in Palu - Center Sulawesi, Kendari - South East Sulawesi, and Ternate North Maluku during three research visits in March, April, May, and July 2019. In addition to conducting FGDs, we conducted interviews and limited discussions during a visit to the mine site of IMIP (Morowali), Virtue Dragon (Konawe), Harita (Obi Island), and local government institutions.

Data from the limited discussion are related to observations made during the visit to the mine site and just after the FGD took place. Interview data is triangulation by matching the results of literature studies (including documents and media articles), field notes, and FGD results.

To obtain AHP and DEMATEL data, we distributed forms to be filled out by FGD participants. In filling out the form of AHP, we explain how to fill in, and we emphasize that the pairwise comparison made by participants is about the severity level of the criteria. The results of such AHP weights will become an input of the Severity component in FMEA.

The way to fill in the AHP form is simple - participants make a pairwise comparison of each criterion and fill in the code into the Saaty scale column. How to fill the AHP form refers to Wadjdi [8]. To analyze AHP weights and their consistency ratio, we refer to Goepel $[15,16]$. 
We explain how to fill in the DEMATEL form to the participants, and we emphasize that the comparison of influence between criteria is focused on the likelihood of occurrence. For example, when the likely occurrence of R1 affects the likelihood of a very strong occurrence of $\mathrm{B} 1$, then the value in the corresponding cell is four. The explanation must be given to participants since the focus of DEMATEL results is directed to be an opportunity component on FMEA. Next, to analyze the DEMATEL data, we refer to Horng et al. [17] and Wadjdi \& Budiastuti [6].

In the FMEA analysis, the numbers on the Severity component are derived from the AHP weights. The numbers in the Occurrence component are from DEMATEL figures. Next, we asked two participants from the Ministry of Defense, who had intelligence operation experiences to fill in the Detectability component on the FMEA form.

\section{Step-3: Analysis and Inferences}

The main question in the case study described above is about the formulation of the policy agenda-setting for mining risk management and its impact on national security.

To produce analysis and inferences aimed at proposing such policy agenda-setting, the AHP, DEMATEL, and FMEA, as described in step 2, must be directed since the step of data collection. The participants, especially to fill out the Detectability component on the FMEA form, must be selected under their expertise, in this case, those who have experiences in security intelligence operations or military operations.

In order to ensure filling in the numbers of Table 2, participants should be explained about the description of Table 1. For example, the category of high costs will cause severity, occurrence, and detectability. Likewise, for the Benefits category, if the benefits are lost, it will present severity, occurrence, and detectability figures. The Risk Priority Number, or RPN, which is the basis for the agenda-setting, is the multiplication of the decision numbers of the three FMEA components. In the formulation of agenda-setting, the vital role of the BOCR approach and the results of the causal mapping are essential because they can be a reference in the scenario formulation and its sequences.

\section{Results}

The result of the FMEA analysis, which also contains the results of AHP and DEMATEL weights, is shown in Table 3, while the mapping is in Figure 2.

Table 2. Result of AHP, DEMATEL, and FMEA.

\begin{tabular}{llcccc}
\hline Code & Issues & Severity & Occurense & Detectability & RPN \\
\hline R1 & Population \& Social Services & 3.78 & 2.94 & 2.10 & 23.33 \\
R2 & Criminal \& Order & 3.40 & 3.59 & 1.70 & 20.76 \\
R3 & Natural Disasters \& Work Accidents & 2.62 & 2.57 & 2.80 & 18.86 \\
R4 & Culture \& Customs & 3.83 & 1.67 & 3.30 & 21.06 \\
R5 & Agreement Violation & 2.32 & 1.67 & 1.70 & 6.57 \\
C1 & Pollution \& Health & 3.63 & 2.07 & 3.30 & 24.76 \\
C2 & Inflation & 3.43 & 1.31 & 2.00 & 8.99 \\
C3 & Depletion of Resources & 3.23 & 2.18 & 3.63 & 25.60
\end{tabular}




\begin{tabular}{llcccc}
\hline Code & Issues & Severity & Occurense & Detectability & RPN \\
\hline O1 & Skills \& Employment & 3.21 & 4.00 & 2.20 & 28.27 \\
O2 & Consultation \& Communication & 3.83 & 1.98 & 3.10 & 23.49 \\
O3 & Participation & 4.00 & 1.67 & 2.20 & 14.66 \\
O4 & Regulations & 1.03 & 1.67 & 1.00 & 1.71 \\
B1 & Revenue \& Tax & 3.46 & 1.67 & 3.13 & 18.02 \\
B2 & Compensation & 3.38 & 1.67 & 3.10 & 17.45 \\
B3 & CSR & 3.65 & 1.77 & 3.10 & 20.08 \\
B4 & Community Development \& Nationalism & 3.92 & 1.98 & 3.70 & 28.71 \\
\hline
\end{tabular}

The overall scenario is sorted by RPN value; see Figure 2A. Logically, the primary responsibility should be given to the largest RPN, and the criteria must be categorized as a causative factor. However, when we assume that a scenario must start with a causative factor, as sketched in Figure 2B, and then we can have at least four scenarios to be the basis of policy agenda-setting. The primary preference for the results of the framework is that the main causative factor is B4 (Community Development and Nationalism), and the effect factor affected in the final sequence is the amendment to regulations and permits.

Noteworthy is the mapping into the BOCR plot is the normalized RPN data (percentage) as the horizontal axis and DEMATEL Results (C-R) as the vertical axis. RPN for each criterion categorized as Risk or Cost is given a negative sign. Negative markings on these criteria are intended as vectors where the higher the RPN value, the criteria must be more prioritized.

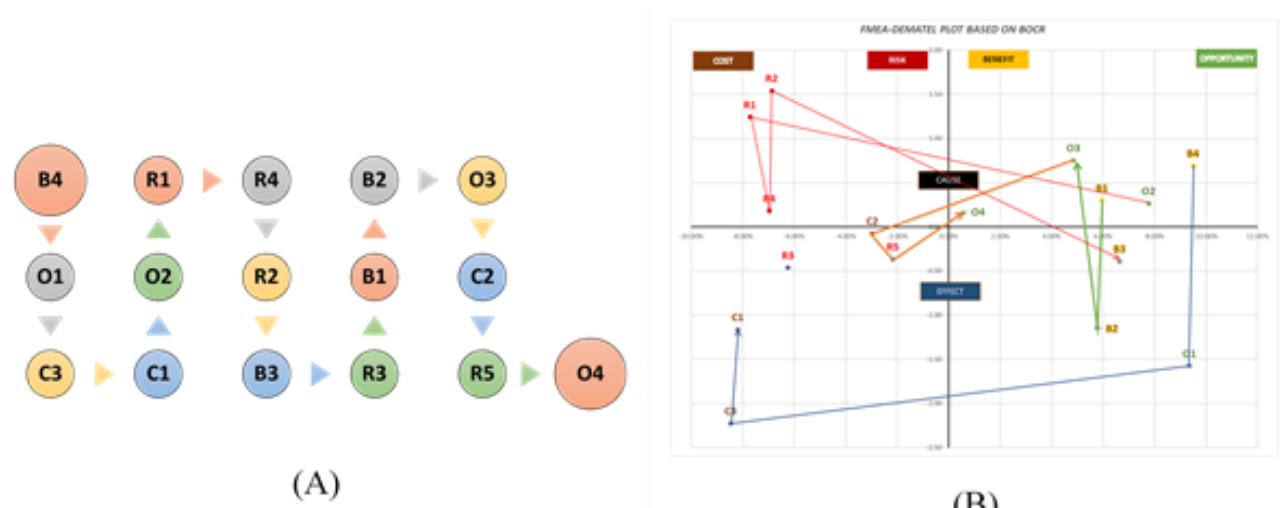

(A)

(B)

Fig. 2. Several ways to infer the results of the AHP-DEMATEL-FMEA to predict scenarios. 


\section{Discussion}

Another alternative in differentiating the AHP-DEMATEL-FMEA framework is a scenario whose design is based on a negative vector or a positive vector. The underlying assumption is the causative factor as the beginning of the scenario made. Based on that idea, we will get an adverse vector scenario that starts with $\mathrm{C} 3$ (loss or depletion of resources) and ends at R5 (Agreement violation), and a favorable vector scenario from B4 (Community development and Nationalism) to $\mathrm{O} 4$ (opportunity to change regulations and permits ).

The exciting thing from this case study based on the perspective of national security is the discovery of Community Development and Nationalism as the primary causal factor. Many research results have widely recommended community development as an essential factor in mining issues; for example, Banks et al. [18]. They state that large-scale mining and the impact of its development are the subjects of controversy and ambiguity. They provoke with the story of the development of local communities in the context of mining in Papua New Guinea. Later, they believe that community development initiatives are a significant way to accept the local community role as an element of capital (although small) and labor (a far more significant part) of the company. So that the local community needs to be empowered because they are the most affected by various factors due to the presence of a mining company.

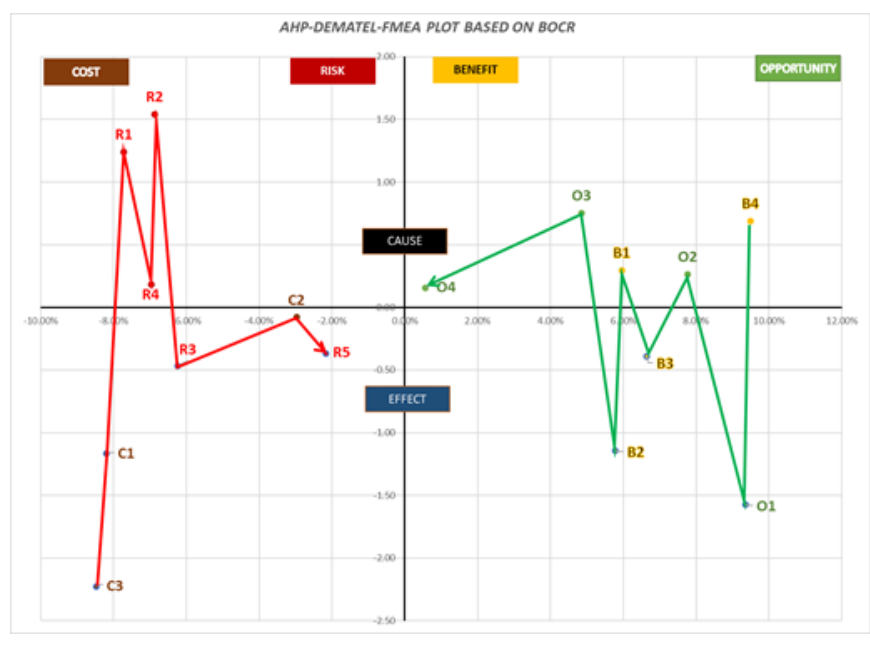

Fig. 3. Scenario-based on negative and positive vectors.

Meanwhile, Murguía \& Böhling [19] considered community development based on community relationship programs that should be emerged as a crucial strategic consideration for mining corporations. In all, we believe that communities around the mining area must be developed and empowered. The fact that when we have visited the mining site and held discussions, participants agreed on the concept of nationalism, such as the state defense movement programs (known as Program Bela Negara), to be socialized to the community, including the mining workers. Such an idea is in line with the scenario where Community 
Development and Nationalism is the primary causal factor. We also see the end of the scenario, which is the chance of amending regulations and permits. In this latter case, some research results to amend regulations and permits are also recommended [20].

When we compare the AHP-DEMATEL-FMEA framework with the results of our previous research [21-23], we think that agenda-setting requires a complex series of data collection and treatment with a variety of tested frameworks. We should conduct the test so that we can compile computational algorithms with accountable results.

As a clue for researchers, the framework we propose is one of the sub-frameworks of a series of frameworks that we are testing to produce a complete computational algorithm to predict an event. However, we hope that the idea of this framework can encourage other researchers to enrich or be able to implement it in making predictive agenda-setting, specifically to support decision making, and in policymaking.

\section{Conclusion}

We conclude that the AHP-DEMATEL-FMEA framework with the BOCR approach is useful in predicting the priority order of responses to risks and impacts that have been identified in such a way that they would become a scenario for formulating policy agenda-setting.

We also find that all factors are cyclical reinforcing. It means that increasing the risk of one factor will increase the risk of other factors, and vice versa, decreasing the chance of an occurring factor will decrease the chance of other occurring factors, and so on.

This study also illustrates that policy issues related to national security and national defense should be on the perspective of multi-discipline if the aim is to support the actual policy process. To support whether individual decisions are taken or not taken at the political level, it is also essential to investigate the existence of a cyclical or non-cyclical risk chain, as we have indicated. Agenda setting can ultimately influence proposals for solutions - and why this must be in line with predictive scenarios involving all cyclical factors.

Finally, we recommend that social research with a critical realist approach will be easily carried out by combining several methods and several analytical techniques, especially in research to support complex decision making as shown in the case studies in this paper.

\section{Acknowledgment}

This paper is produced in line with the Research Project of Tambang Asing dalam Perspektif Pertahanan Negara at The Research Center of Defense Resources - Research and Development Agency - Ministry of Defense, Indonesia (Puslitbang Sumdahan Balitbang Kemhan). So that we are thankful for the chief "Brig-Gen Martono," which provided permittance and support for the use of the data for this paper. We would also like to thank the team members of the project. Their feedback contributed to the current version of this paper. Moreover, we would like to thank Colonel Ridwan for his valuable suggestions that criticize the framework logic of this paper. 


\section{References}

[1] Chen RH, Lin Y, Tseng ML. Multicriteria analysis of sustainable development indicators in the construction minerals industry in China. Resour Policy. 2015;

[2] Huang IB, Keisler J, Linkov I. Multi-criteria decision analysis in environmental sciences: Ten years of applications and trends. Science of the Total Environment. 2011.

[3] Yang $\mathrm{MH}, \mathrm{Su} \mathrm{CH}$, Wang WC. Use of hybrid MCDM model in evaluation for cloud service application improvement. Eurasip J Wirel Commun Netw. 2018;

[4] Park J, Park C, Ahn S. Assessment of structural risks using the fuzzy weighted Euclidean FMEA and block diagram analysis. Int J Adv Manuf Technol. 2018;

[5] Chiozza ML, Ponzetti C. FMEA: A model for reducing medical errors. Clin Chim Acta [Internet]. 2009;404(1):75-8. Available from: http://dx.doi.org/10.1016/j.cca.2009.03.015

[6] Wadjdi AF, Budiastuti D. E-gov adoption model of the military organization in Indonesia. In: Proceedings - 2015 International Conference on Science in Information Technology: Big Data Spectrum for Future Information Economy, ICSITech 2015. 2016.

[7] Sipahi S, Timor M. The analytic hierarchy process and analytic network process: An overview of applications. Vol. 48, Management Decision. 2010. p. 775-808.

[8] Wadjdi AF, Sianturi EM, Ruslinawaty N. Design of data collection form to ensure consistency in AHP. In: Proceedings of 2018 10th International Conference on Information Technology and Electrical Engineering: Smart Technology for Better Society, ICITEE 2018 [Internet]. Denpasar, Bali, Indonesia: IEEE; 2018. Available from: https://ieeexplore.ieee.org/document/8534751

[9] Sarmiento R, Vargas-Berrones KX. Modeling the implementation of green initiatives: An AHPBOCR approach. Cogent Eng [Internet]. 2018;5(1):1-18. Available from: http://doi.org/10.1080/23311916.2018.1432120

[10] Kumar A, Kaviani MA, Hafezalkotob A, Zavadskas EK. Evaluating innovation capabilities of real estate firms: a combined fuzzy Delphi and DEMATEL approach. Int J Strateg Prop Manag. 2017; [11] Gandhi S, Mangla SK, Kumar P, Kumar D. A combined approach using AHP and DEMATEL for evaluating success factors in implementation of green supply chain management in Indian manufacturing industries. Int J Logist Res Appl. 2016;

[12] Baykasoğlu A, Kaplanoglu V, Durmuşoglu ZDU, Şahin C. Integrating fuzzy DEMATEL and fuzzy hierarchical TOPSIS methods for truck selection. In: Expert Systems with Applications. 2013.

[13] Vinodh S, Swarnakar V. Lean Six Sigma project selection using hybrid approach based on fuzzy DEMATEL-ANP-TOPSIS. Int J Lean Six Sigma. 2015;

[14] Chang KH, Chang YC, Lee YT. Integrating TOPSIS and DEMATEL methods to rank the risk of failure of FMEA. Int J Inf Technol Decis Mak. 2014;

[15] Goepel KD. Implementing the Analytic Hierarchy Process as a Standard Method for MultiCriteria Decision Making in Corporate Enterprises - a New AHP Excel Template with Multiple Inputs. In 2013.

[16] Goepel KD. AHP calculator - AHP-OS [Internet]. BPMSG; 2017 [cited 2018 Jan 23]. Available from: https://bpmsg.com/academic/ahp_calc.php

[17] Horng JS, Liu CHS, Chou SF, Tsai CY, Hu DC. Developing a sustainable service innovation framework for the hospitality industry. Int J Contemp Hosp Manag. 2018;

[18] Banks G, Kuir-Ayius D, Kombako D, Sagir BF. Dissecting Corporate Community Development in the Large-Scale Melanesian Mining Sector. Large-scale Mines Local-level Polit Between New Caledonia Papua New Guinea. 2017;207-28.

[19] Murguía DI, Böhling K. Sustainability reporting on large-scale mining conflicts: The case of Bajo de la Alumbrera, Argentina. J Clean Prod [Internet]. 2013;41:202-9. Available from: http://dx.doi.org/10.1016/j.jclepro.2012.10.012 
[20] Nwapi C. Legal and institutional frameworks for community development agreements in the mining sector in Africa. Extr Ind Soc [Internet]. 2017;4(1):202-15. Available from: http://dx.doi.org/10.1016/j.exis.2016.11.010

[21] Wadjdi AF, Rustandi A. Selection Of Marine Patrol Organizing System: A Case Study For Indonesia. In 2018.

[22] Wadjdi AF, Sianturi EM. The Implementation of Framing, Agenda-Setting, and Data Mining in Evaluation of Public Policies Case Study of the State Defense Program in Indonesia. In: 2018 2nd International Conference on Informatics and Computational Sciences (ICICoS), 10/2018. 2018.

[23] Wadjdi AF, Suhirwan, Firdaus Y. Hybrid framework of decision making in military: Case study of railway planning. In: IOP Conference Series: Earth and Environmental Science. Institute of Physics Publishing; 2018. 